Revista Herencia, Vol. 31 (2), julio-diciembre, 2018.

\title{
LA FUENTE DE CUPIDO Y EL CISNE EN LA UNIVERSIDAD DE COSTA RICA
}

\author{
The Cupid and Swan fountain in the University of Costa Rica
}

\author{
Sergio Orozco Abarca \\ Universidad de Costa Rica, Costa Rica \\ sergiorozco@gmail.com
}

Recibido: $04-11-2018$

Aprobado: 31-11-2018

\begin{abstract}
Sergio Orozco Abarca es graduado en Filología Española, por la Universidad de Costa Rica. Ensayista e investigador de temas culturales, se ha concentrado en la historia de la fundición artística, proveniente de Europa, en especial las fuentes victorianas de hierro colado. Varios de sus artículos se han publicado en periódicos nacionales y en revistas especializadas del exterior. Premio 18 de Abril (ICOMOS, Costa Rica), año 2018.
\end{abstract}

\section{RESUMEN}

La fuente Cupido y el Cisne llegó a Costa Rica, proveniente de Inglaterra, en diciembre de 1867, y fue instalada en el parque Central de San José al año siguiente, para conmemorar la primera cañería subterránea de la capital. En el año 1944 fue donada a la Universidad de Costa Rica, fundada en 1940. La fuente permaneció frente al edificio de la Universidad, hasta que su último vestigio fue trasladado en el año 1966. La fuente pasó a la Ciudad Universitaria, en San Pedro de Montes de Oca, y su primer asiento allí fue el edificio de la facultad de Agronomía, inaugurado en 1972. A finales de la década de 1980, se determinó restaurar la fuente e instalarla en la plaza Santo Tomás, frente a la Biblioteca Carlos Monge Alfaro. En el año 2018, la fuente celebra un siglo y medio de existencia.

Palabras clave: fuente; hierro colado; Universidad de Costa Rica; Ciudad Universitaria; cañería; barrio González Lahmann; Jorge Mario Delgado; plaza Santo Tomás

\begin{abstract}
The Cupid and Swan fountain (also known as Boy and Swan fountain) arrived in Costa Rica from England in December 1867 and was installed in the Central Park of San Jose, the following year to commemorate the capital's first iron pipe. In 1944 it was donated to the University of Costa Rica, founded in 1944. The fountain remained in the University building, until its last vestige was moved in 1966. The fountain was moved to the Ciudad Universitaria, in San Pedro de Montes de Oca, and its first seat there was the Agronomy faculty building, inaugurated in 1972. At the end of the 1980s, it was decided to restore the fountain and install it in Plaza Santo Tomás, in front of the Carlos Monge Alfaro Library. In 2018, the fountain celebrates a century and a half of existence.
\end{abstract}

Keywords: fountain; cast iron; University of Costa Rica; Ciudad Universitaria; piping; González Lahmann neighborhood; Jorge Mario Delgado; plaza Santo Tomás 
La fuente Cupido y el Cisne de Costa Rica fue adquirida en Inglaterra, en el año 1867, por el director de obras públicas Ángel Miguel Velázquez. Fue ella uno de los monumentos destinados a engalanar San José, con motivo de la inauguración del primer acueducto capitalino, el día 25 de octubre de 1868. Sus orígenes se remontan a la Revolución Industrial y a la Era Victoriana, pero en este artículo partiremos del momento en que arribó a nuestro país, el 25 de diciembre de 1867, a bordo de la fragata William Le Lacheur.

Salida de los altos hornos de Coalbrookdale, en el condado de Shropshire, Inglaterra, nuestra fuente es una réplica de la fuente original, que se conserva en muy buen estado en el "Museo del Hierro de Ironbridge" (Coalbrookdale) ${ }^{1}$. Se desconoce la cantidad exacta de réplicas que se hicieron, pues se perdieron muchos registros de la compañía fabricante; pero se sabe, con certeza, que sobreviven apenas seis ejemplares en el mundo (Powell, 2012). Uno de ellos es nuestra fuente "Cupido y el Cisne", que hoy luce esplendorosa frente a la biblioteca Carlos Monge Alfaro, de la Universidad de Costa Rica.

Todos los materiales que el Ing. Velázquez trajo de Inglaterra para la cañería, incluyendo la fuente y una esplendorosa verja perimetral para el parque, se apilaron, en grandes lotes de hierro, en la esquina noreste del parque Central, para asombro de grandes y chicos (Anónimo, 1928).

La fuente se instaló en el centro del parque, y no solo sirvió para adorno y esparcimiento de multitudes por generaciones, sino como el surtidor de agua limpia para muchas personas, pues muy pocas poseían recursos para costear una paja de agua directamente en sus casas. Antes del tendido de la cañería, el agua para las casas se obtenía de las acequias o de los pozos de mampostería, casi sin tratamiento. La purificación del agua, empero, no ocurrió de golpe. Se gestó en un largo proceso de prueba y error, pero aquel fue el principio, con la fuente como símbolo. Allí, impertérrita, permaneció la fuente por más de 7 décadas, hasta que la Municipalidad de San José, en el año 1943, decidió construir un gran quiosco en el centro del parque, por lo que la fuente quedó desamparada.

\footnotetext{
${ }^{1}$ Para más información acerca de la fuente original Cupido y el Cisne, ubicada en el Reino Unido, consulte el artículo de Sergio Orozco Abarca "Delfines, leones y tritones; fuentes victorianas de hierro en plazas y parques de Costa Rica (1868-1880), publicado en Herencia Vol. 29, Núm. 1 (2016).
} 
Figura $\mathbf{N}^{\circ}$ 1. Fuente Cupido y el Cisne en sus inicios, en la plaza Principal de San José. Autor desconocido. Década de 1870.

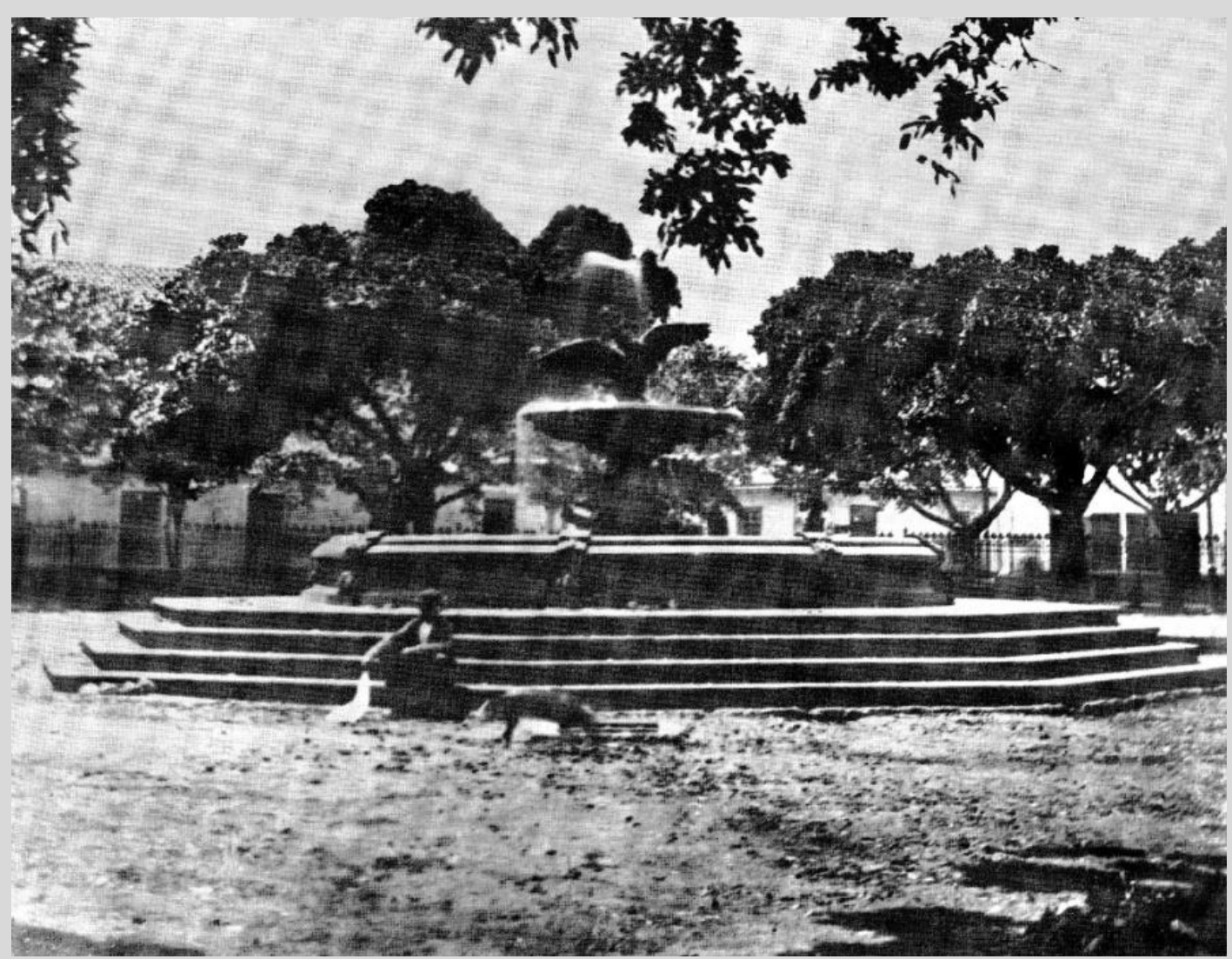

Primero, la Municipalidad pretendió donarla al nuevo Aeropuerto, construido en la Sabana (Núñez, 1944). Sin embargo, las autoridades universitarias se enteran de este propósito y la pidieron a la Municipalidad, que accedió donarla a la institución.

El destino elegido para instalarla fue una pequeña rotonda enfrente del edificio central de la Universidad, en Barrio González Lahmann, inaugurado en 1941. Este edificio, con el frente hacia la calle 17, comprendía la rectoría, oficinas, aulas y la Sala Magna o Paraninfo. Más allá, al oeste, seguía una plaza conocida como el Potrero de los Gallegos, porque aquellos fueron terrenos que en el siglo XIX pertenecieron a don Felipe Gallegos Quesada y familia. 
Figura N². Fuente Cupido y el Cisne en la Universidad de Costa Rica, barrio González Lahmann. El edificio frontal era la Sala Magna, también conocido como Paraninfo. La zona llena de césped, al oeste de la fuente era conocida como el Potrero de los Gallegos. Foto de autor desconocido, sin fecha determinada (entre 1944 y 1959).

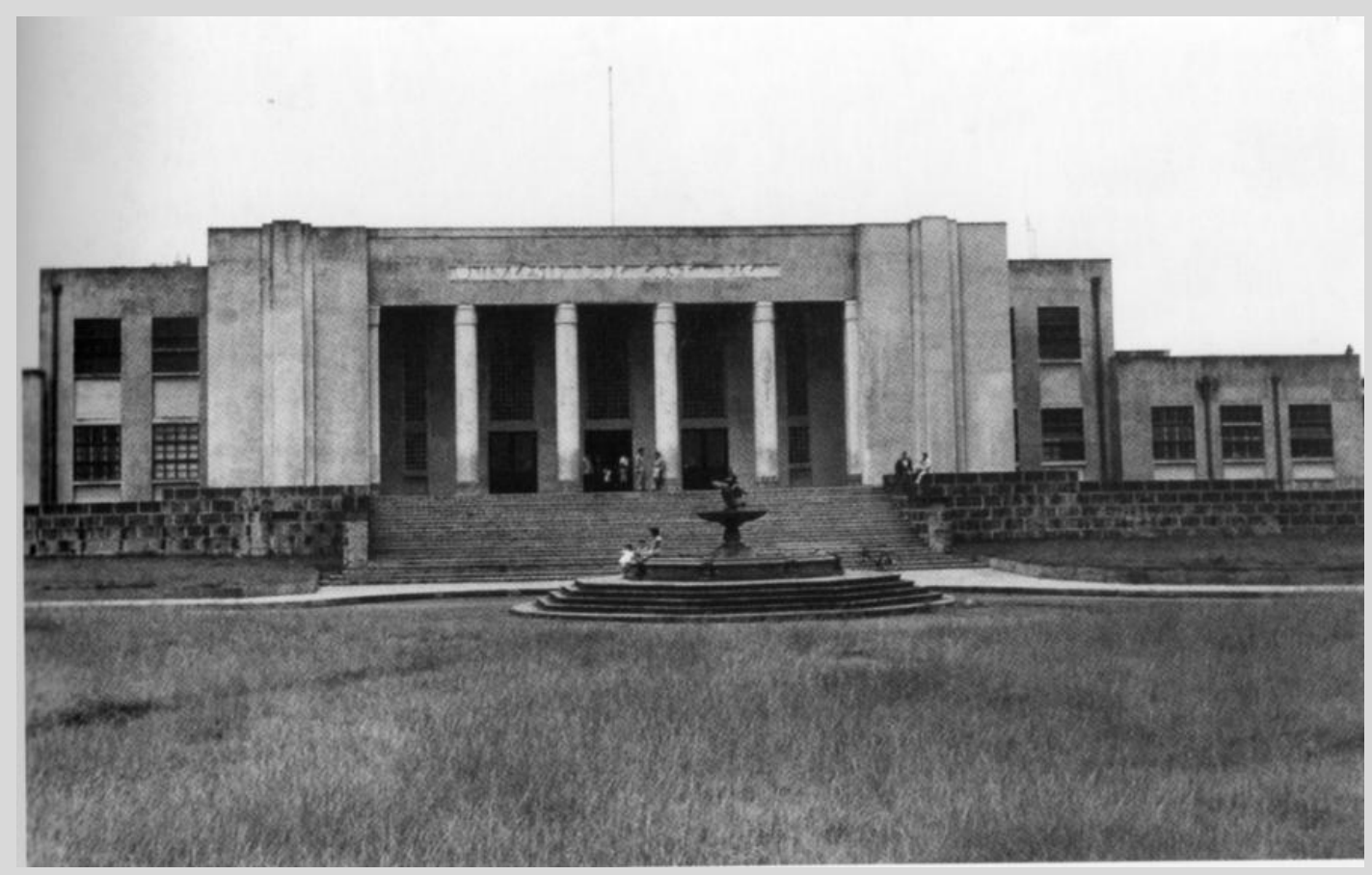

Ya para el mes de marzo de 1944, justo al final del período del primer rector oficial de la Universidad, Lic. Alejandro Alvarado Quirós, la fuente (con su pileta de hierro y escalinata de piedra) quedó totalmente instalada. Tiempo después, a finales de 1944 o inicios de 1945 se construyó el pavimento de concreto de la rotonda. 
Figura $\mathbf{N}^{\circ}$ 3. El frente de la Universidad mirando de norte a sur, en la que se aprecia al centro de la foto, el busto del Dr. Clorito Picado (1887-1944), que actualmente se encuentra en el Campus Universitario; y a la derecha, la fuente Cupido y el Cisne. El vehículo transita por la avenida $6^{a}$. Foto publicada en páginas de Facebook, por don Jaime Salazar. Circa 1956.

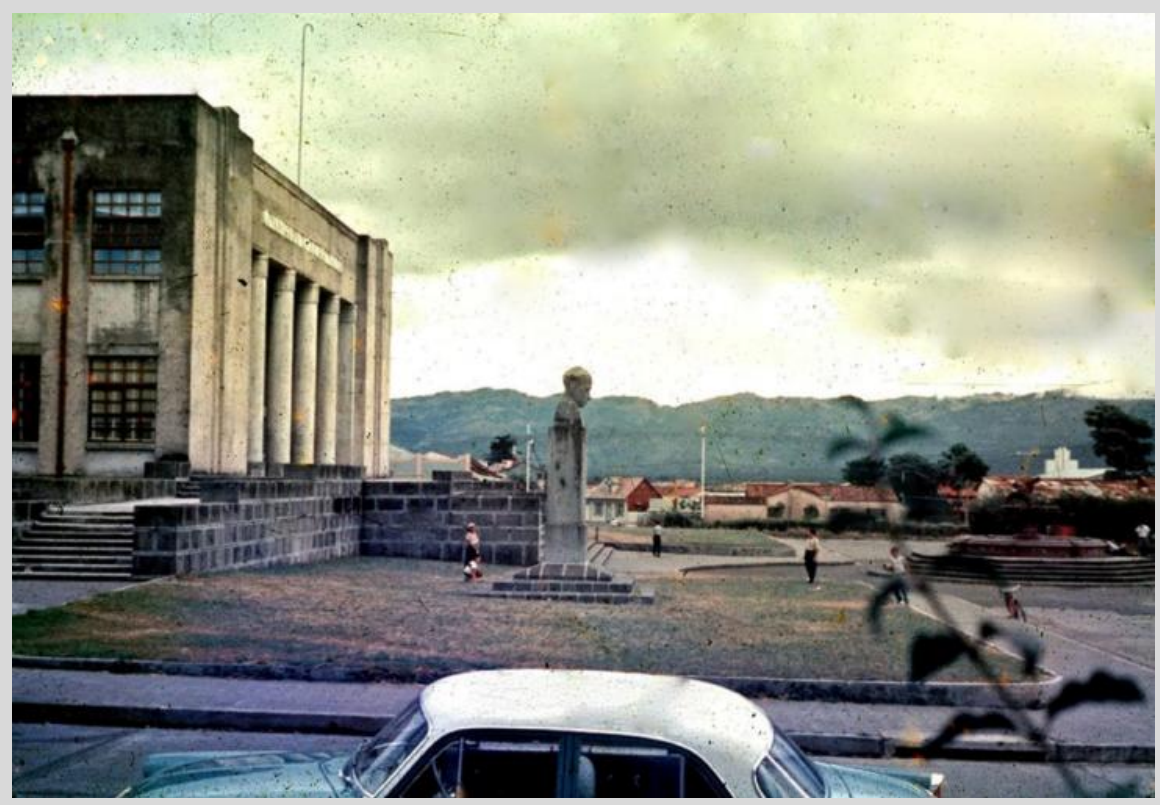

Figura N4. Reinas Universitarias en la fuente. Fotografía donde se aprecia a las candidatas al reinado universitario, del año 1952. La ganadora fue la Srta. Matilde Marín, de la Escuela de Ciencias Económicas y sociales, coronada luego en un gran baile, el día 30 de agosto. Foto Carrillo, publicada en La República, 22 de agosto de 1952. SINABI.

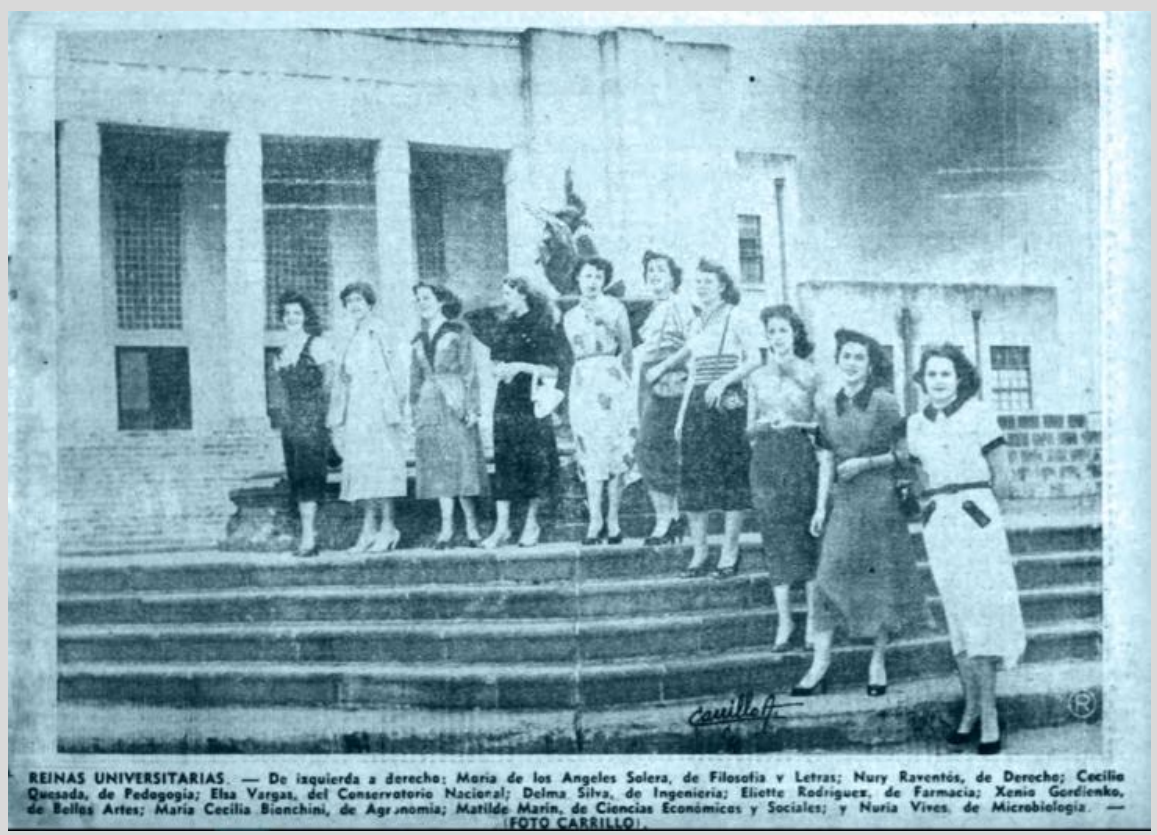


Figura $\mathbf{N}^{\circ} \mathbf{5}$. Unas hermosas niñas juegan frente al busto del Dr. Clorito Picado, mientras unos jóvenes descansan en la fuente. Foto publicada en páginas de Facebook, por don Jaime Salazar. Circa 1956.

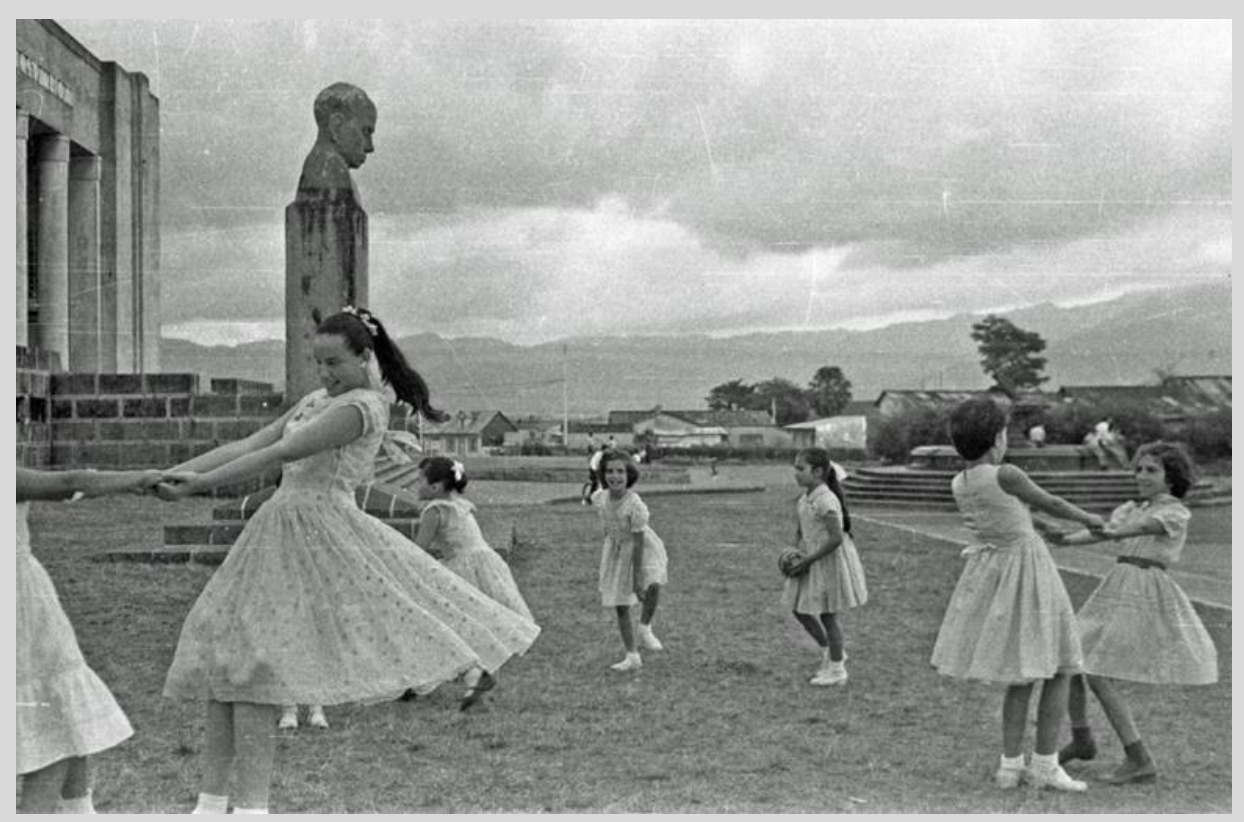

En la década de 1950, la Universidad inició la construcción de la Ciudad Universitaria, en San Pedro de Montes de Oca. El primer edificio fue el de la Facultad de Ingeniería, finalizado en 1953. A partir de ese año, y hasta 1957, las diferentes unidades académicas fabricaron edificios en el nuevo Campus, por lo que en el año 1958, ya casi todos los edificios antiguos de la sede en González Lahmann, estaban vacíos.

En vista de que la fuente también había perdido seguridad y vigilancia, en abril de ese año, el Lic. Rodrigo Facio Brenes, solicitó al Presidente Municipal, don Jaime Tormo, el permiso para trasladar la fuente al nuevo Campus.

Me es grato comunicarle que el Consejo Universitario en su sesión 935 de 28 de abril, artículo 39, me dio instrucciones para dirigirme a esa Honorable Corporación, solicitando su permiso para trasladar la fuente que se halla frente a los edificios de la Universidad en barrio González Lahmann, a los terrenos de la Ciudad Universitaria en San Pedro de Montes de Oca. Me refiero a la fuente que por muchos años estuvo en el centro del parque Central, y que, a solicitud de la Universidad, en momentos en que esta se restablecía, fue ubicada enfrente de lo que entonces era su edificio central, y que a solicitud de la Universidad, en momentos en que esta se restablecía, fue ubicada en lo que entonces era su edificio central. Como todos los servicios de la universidad se han ido trasladando a la Ciudad Universitaria, ya no se puede ejercer sobre esa fuente los cuidados y vigilancia que en otra hora se practicaron, y se corre el peligro de que pueda dañarse e incluso perderse, Por otro la colocación de la fuente en la Ciudad Universitaria implicaría guardar adecuadamente en el seno de una institución nueva y moderna un agradable recuerdo de tiempos pasados de la ciudad de San José (Carta No. R-364-58. AUROL) 
La solicitud fue aprobada por la Municipalidad, pero la fuente se mantuvo en su sitio por varios años.

Partes de la fuente (incluyendo el cisne) fueron cayendo por el deterioro. En noviembre de 1966 (Núñez, 1966) se elimina y traslada la pileta de hierro, el último vestigio de la fuente. Desmantelada e incompleta, pasó la fuente a un predio contiguo a los talleres de carpintería y transportes (al oeste de la actual Rectoría), en la nueva Ciudad Universitaria.

Figura No6. Detalle de los trozos de fuente tirados en el predio, al oeste de los talleres de carpintería y transportes. La Nación, 20 de junio de 1974.

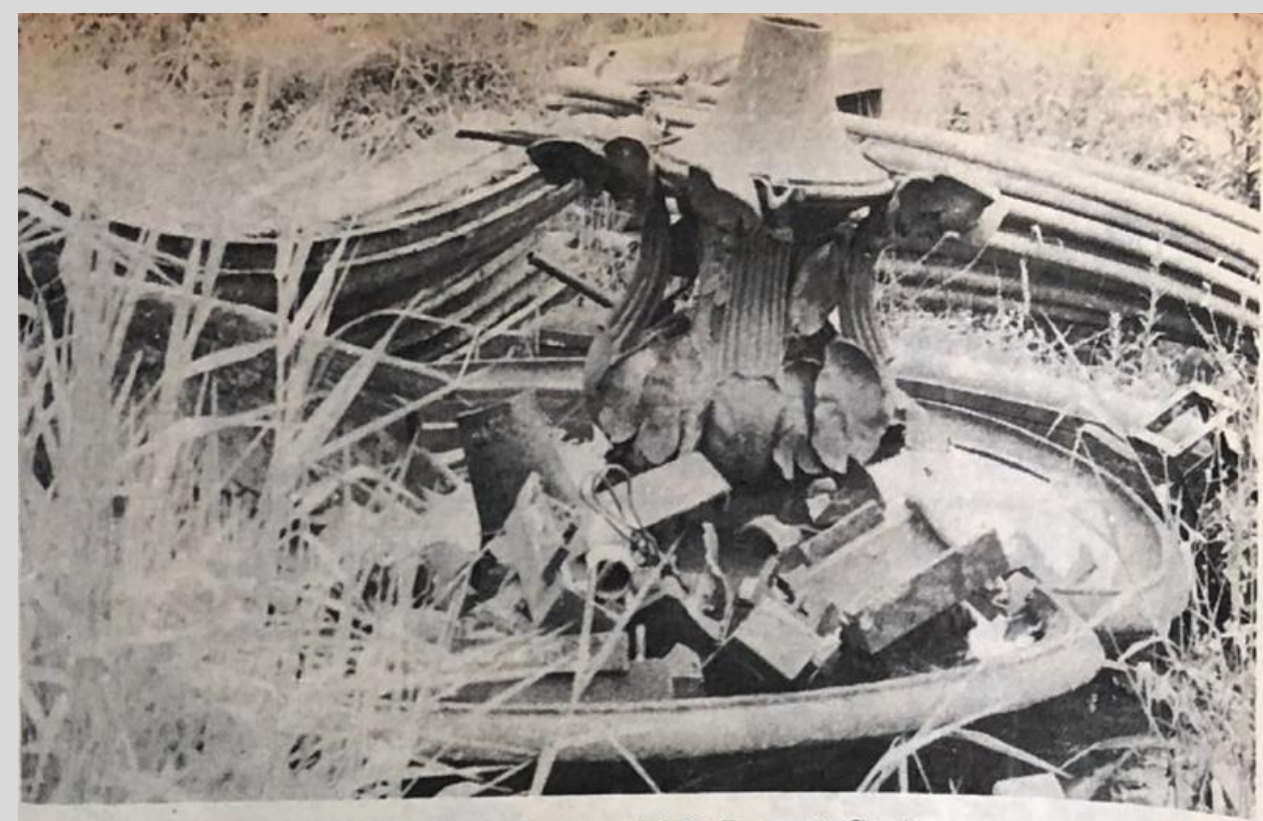

Hecha añicos está la vieja fuente del Parque Ceñtral, y que fue traida rara la inauguración, en 1868 , de la primera cañería con tubos "de fie. rro" de la ciudad de San José. Pero no se crea que la fotografia se tomó en un charral de los suburbios capitalinos; nada de eso, pues fue captada dentro del "campus" de la Universidad de Costa Rica.

Es en este momento cuando surge la figura heroica, tesonera y salvadora del Ing. Jorge Mario Delgado Madrigal (1926-2015), quien se desempeñaba como Secretario de la Facultad de Agronomía. En el año 1969, el Ing. Delgado vio la fuente abandonada en aquel sitio, y sabiendo además que otras partes de ella estaban en un plantel del MOPT, se propuso reunir todas sus piezas, repararla e instalarla en uno de los jardines internos del nuevo edificio de la Facultad de Agronomía, cuya construcción se iniciaba en aquel año. 
Figura $\mathbf{N}^{\circ}$ 7. El héroe de la fuente: Ing. Jorge Mario Delgado, en su época de profesor universitario. Foto de autor y fecha desconocidos. Colección fotográfica Universidad de Costa Rica, AUROL.

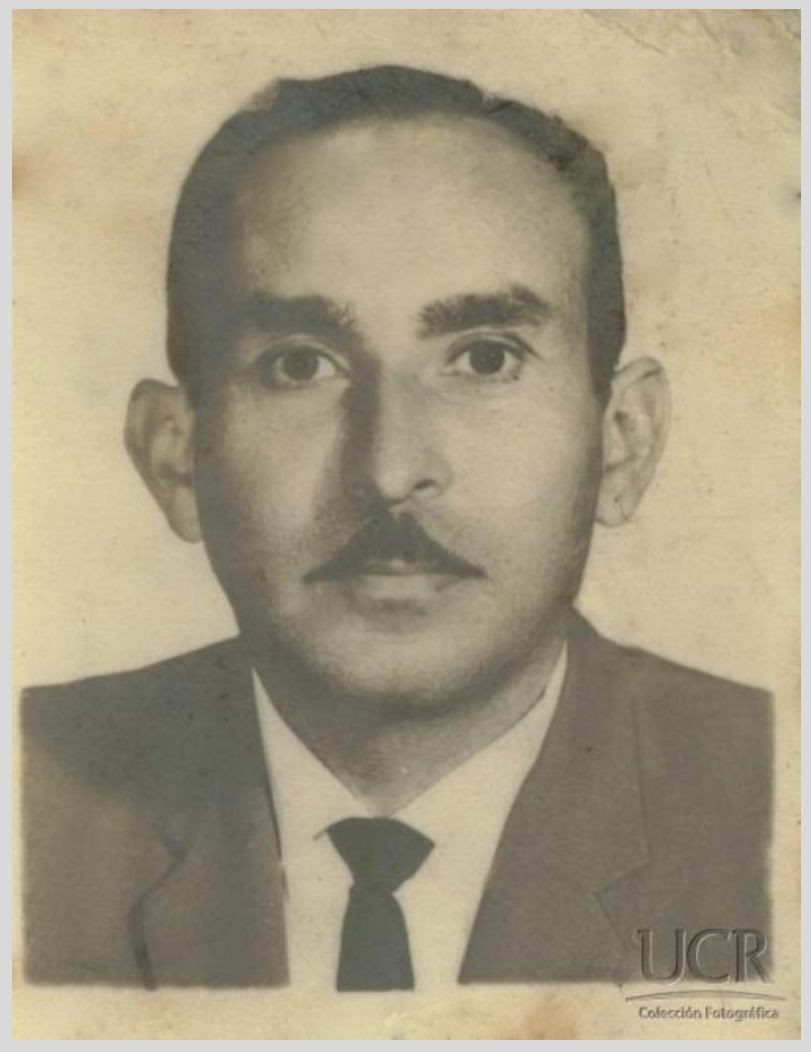

Gracias al apoyo del Director Administrativo de la Universidad, prof. Carlos Caamaño Reyes, se hizo la solicitud formal ante el Consejo Universitario, que finalmente la aprobó.

Obtenida la anuencia del Consejo, don Jorge Mario, junto con un grupo de entusiastas alumnos, reunieron las partes de la fuente. Con el apoyo del Ing. Jorge Nanne Michaud, Jefe de Parques de la Municipalidad de San José, se inició la restauración, en los talleres de la Municipalidad. Se habían perdido varias piezas pequeñas, tanto del plato como del fuste, así que don Juan Chirino Paniagua, dueño de la Fundición Chirino, ubicada en el Paso de la Vaca, modeló y fundió tales piezas, sin cobrar un centavo a la Universidad (Delgado, s.f., p. 8). La Fundición Chirino, fundada en 1945, se especializaba en la fabricación de tapas de alcantarillado, hidrantes, campanas para iglesias y pesas para ejercicios. 
Figura $\mathbf{N}^{` 8}$. El Cómplice: Ing. Herbert Nanne Michaud. Foto de autor y fecha desconocidos. Colección fotográfica Universidad de Costa Rica, AUROL.

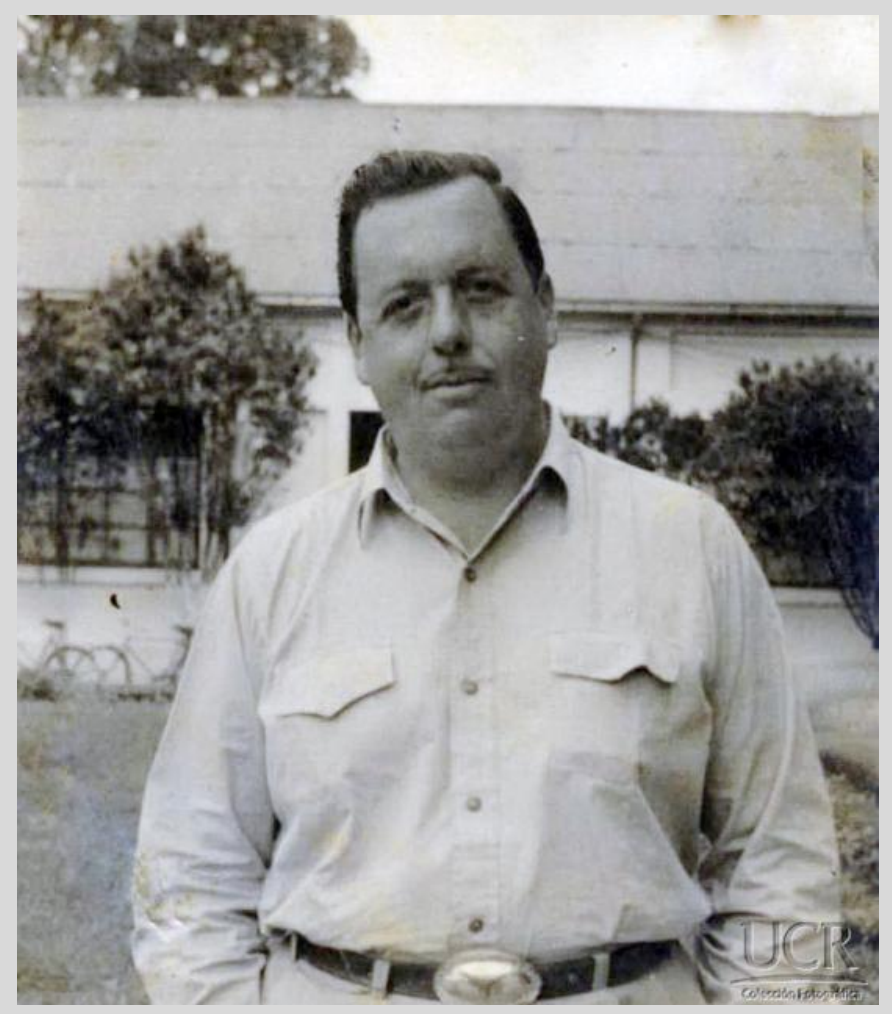

Finalmente, el edificio nuevo de la facultad de Agronomía se inauguró en 1972, y la fuente fue colocada en un patio interno, a inicios de 1973.

En la siguiente cita, el mismo don Jorge Mario Delgado, con gran emoción e inspiración por el deber cumplido, nos narra su increíble experiencia de la restauración de la fuente:

El honor conferido de instalar la fuente fue grande, pero grande también el compromiso contraído. Consciente de esta realidad, asumí personalmente la tarea de restauración e instalación. El reto fue bastante serio pues estábamos tratando con un material (si bien es cierto, de hierro), que pasaba de los cien años; así que con operarios de la unidad de mantenimiento de la Universidad, inicié la tarea. Por razones de espacio y estética se prescindió de la escalinata. La levantamos sobre una loza de concreto previamente chorreada a nivel del suelo (y de forma hexagonal), que representara justamente la parte superior de ella. Poco a poco, todos y cada uno de sus componentes se fueron ensamblando hasta que su estructura quedó totalmente armada y en perfecto funcionamiento. Sin modificación de ninguna clase, para el abasto de agua se construyó un depósito con una bomba sumergida, encargada de reciclar el agua y evitar el desperdicio. En el fondo del estanque se colocaron unos reflectores que iluminaban el agua y la cascada del plato (Delgado s.f., p.10). 
Figura N9. Una de las últimas fotos del Ing. Jorge Mario Delgado, quien posa con documentos relacionados con la historia de la fuente. La foto fue tomada en su casa de habitación, en San Rafael de Escazú. El Ing. Delgado fue la primera persona en crear un texto completo (inédito) acerca de la historia de la fuente. Foto: Sergio Orozco Abarca, 5 de marzo de 2014.

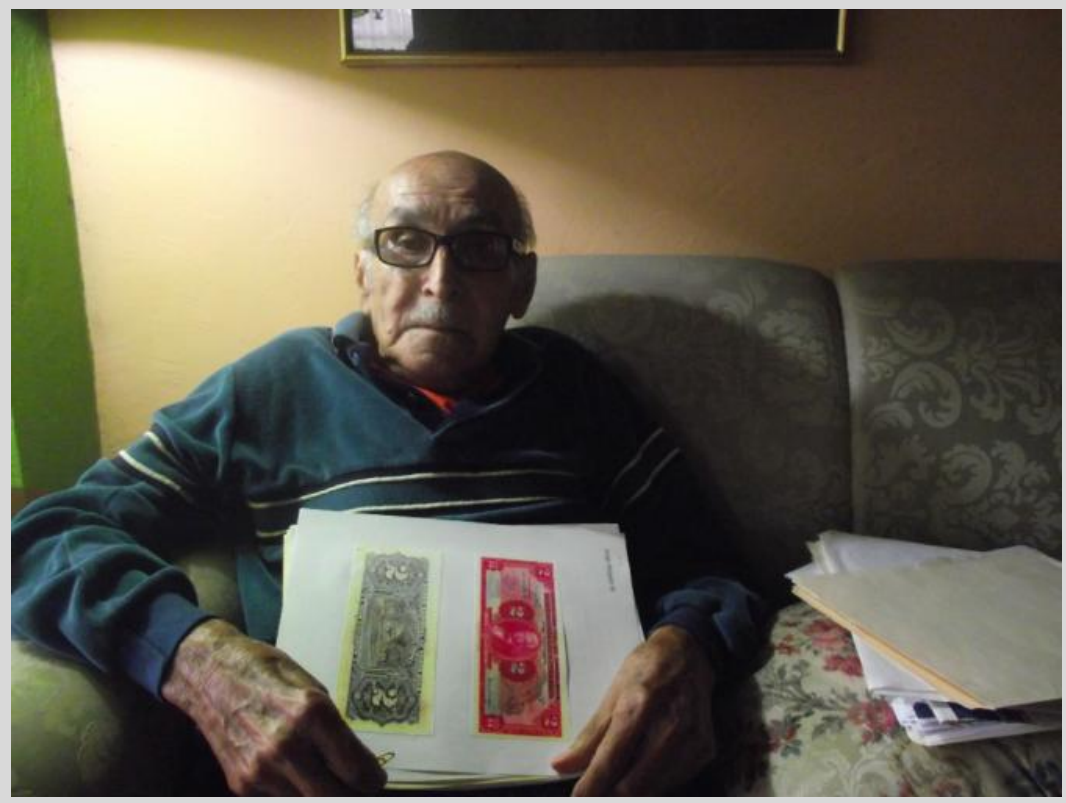

En Agronomía, la fuente se convirtió en un verdadero hito, el elemento central del edificio de la facultad, donde todos los profesores y alumnos solían tomar descanso y hacerse fotografías.

Figura N¹0. Edificio de la Escuela y Facultad de Agronomía. Foto del año 1977. Autor desconocido. Colección fotográfica Universidad de Costa Rica, AUROL.

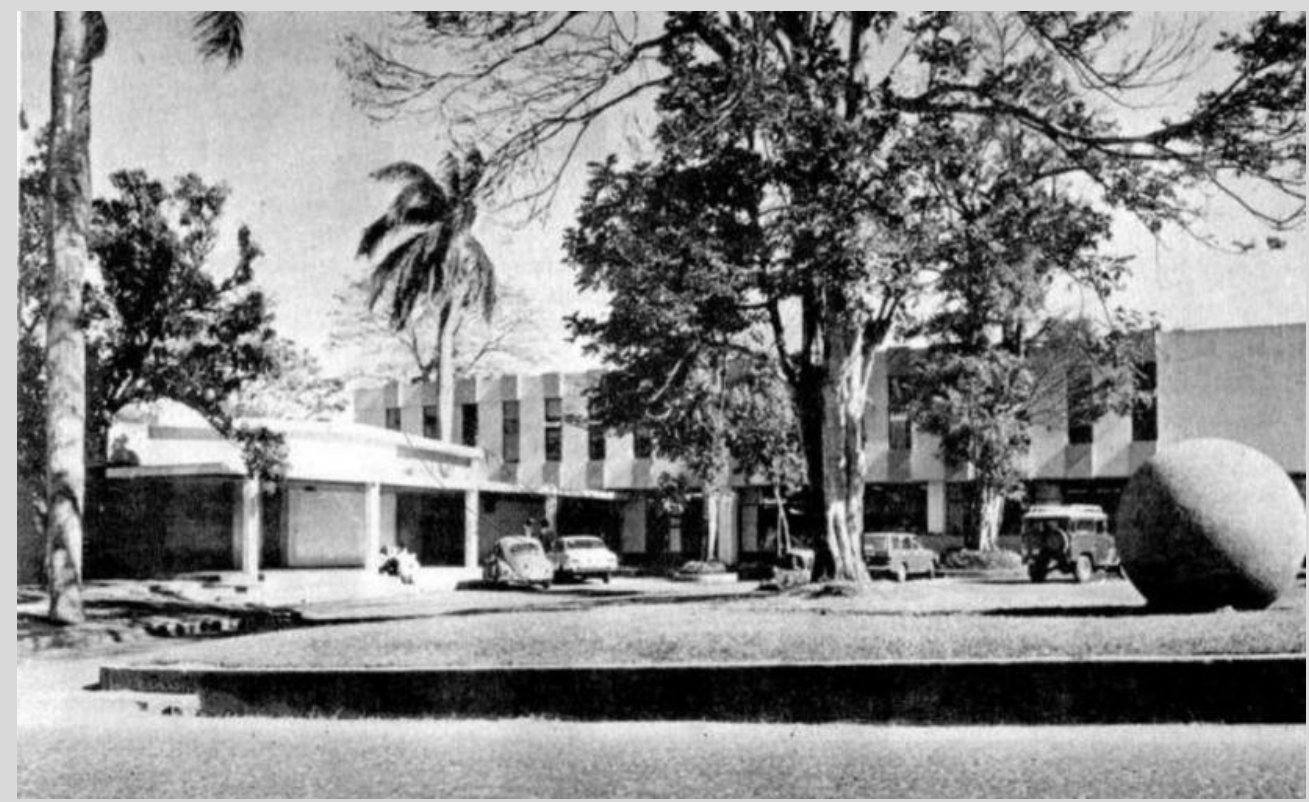


Figura N¹1. Agronomía. Promoción del segundo semestre de 1975. Sin más datos. Colección fotográfica Universidad de Costa Rica, AUROL.

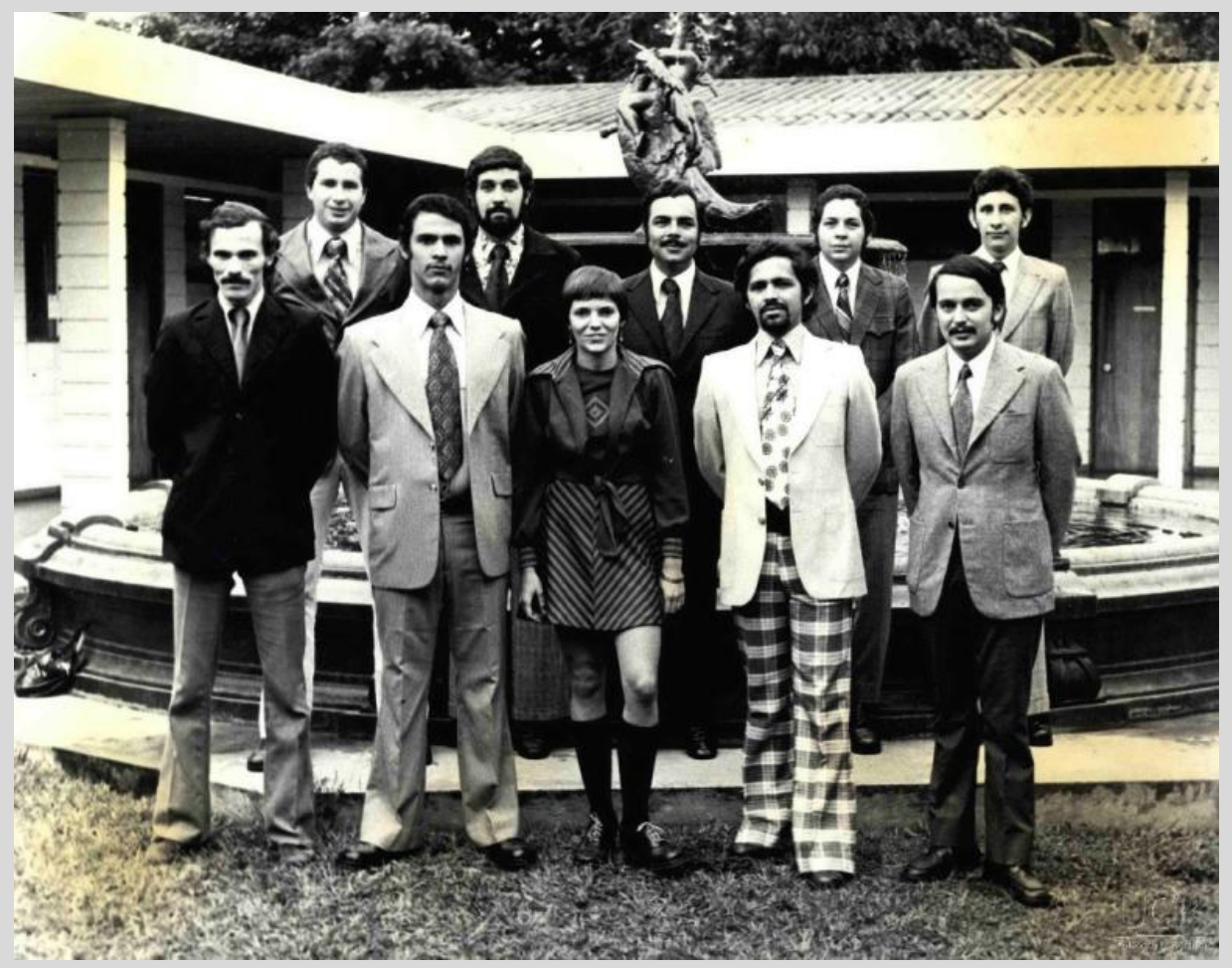

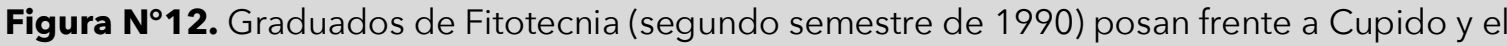
Cisne, en el patio interno de la Facultad de Agronomía. Foto cortesía de Édgar Rojas Cabezas, gracias a la colaboración de Luis Fernando Campos Vargas.

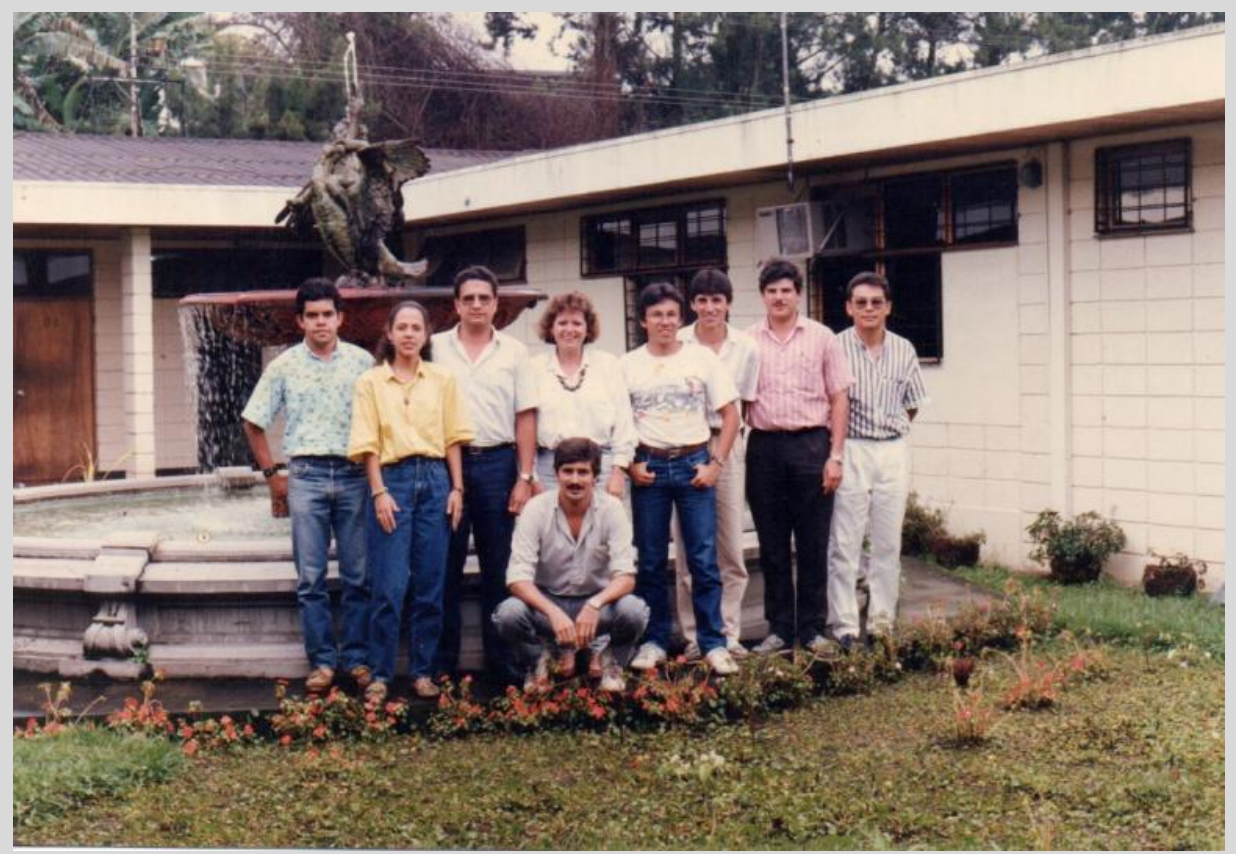


En la década de 1980 se presentó ante el Consejo Universitario un programa de desarrollo urbanístico de los alrededores de la Universidad, para constituir un proyecto denominado "Distrito Universitario", cuya idea original databa de la década anterior (Actas del Consejo Universitario de la Universidad de Costa Rica. Sesión No.3544, ordinaria, 28 de febrero de 1989. Art 4º.).

En el año 1987, el arquitecto Luis Fernando Aronne Castro, que fungía como director de OEPI (Oficina Ejecutora del Programa de Inversiones), junto con el rector Fernando Durán Ayanegui, empezaron las gestiones para colocar la fuente en un lugar más visible y asequible.

Es por ello que el proyecto destinó parte de los recursos para construir una plaza, que llevaría la fuente en su centro. A un costado de dicha plaza, del lado del parqueo de la Facultad de Ingeniería, se levantaría un mural para mostrar, en uno de sus lados, la historia de la fuente, y por el otro, la historia de la Universidad de Santo Tomás. En el otro extremo de la plaza se erigiría una estatua al ex rector, don Rodrigo Facio Brenes, en virtud de que la ciudad universitaria llevaba su nombre, pero no existía un monumento en su memoria.

Dicha plaza comprendería el espacio del parqueo de Ingeniería, la calle sur frente a la biblioteca (desde dicho parqueo, hasta más allá del edificio de Estudios Generales y del edificio Saprissa).

El proyecto del Distrito Universitario se ampliaría a las calles aledañas hasta el sector del Colegio Vargas Calvo. A la calle que se extiende del Colegio Vargas Calvo hasta el Colegio Calasanz, se le agregarían árboles ornamentales. Por lo tanto, los dineros que se destinarían a otras construcciones en el cantón, se concentrarían en los alrededores de la Universidad (Actas del Consejo Universitario de la Universidad de Costa Rica. Sesión No.3544, ordinaria, 28 de febrero de 1989. Art $4^{\circ}$ ).

En febrero de 1989 se retoma el proyecto, en coordinación con la Municipalidad de Montes de Oca y otras organizaciones del Cantón. Simultáneamente, la Universidad recibió un ofrecimiento de la entonces diputada Rosemary Karpinsky Dodero, para iniciar la primera etapa del proyecto, con unas partidas específicas destinadas a obras en el Cantón de Montes de Oca, que serían canalizadas por medio del Ministerio de Obras Públicas y Transportes (Delgado. s.f., p. 16). 
Revista Herencia, Vol. 31 (2), julio-diciembre, 2018.

Figura $\mathbf{N}^{\circ}$ 13. Grabado del proyecto Distrito Universitario. Imagen cortesía de Arq. Luis Fernando Aronne Castro.

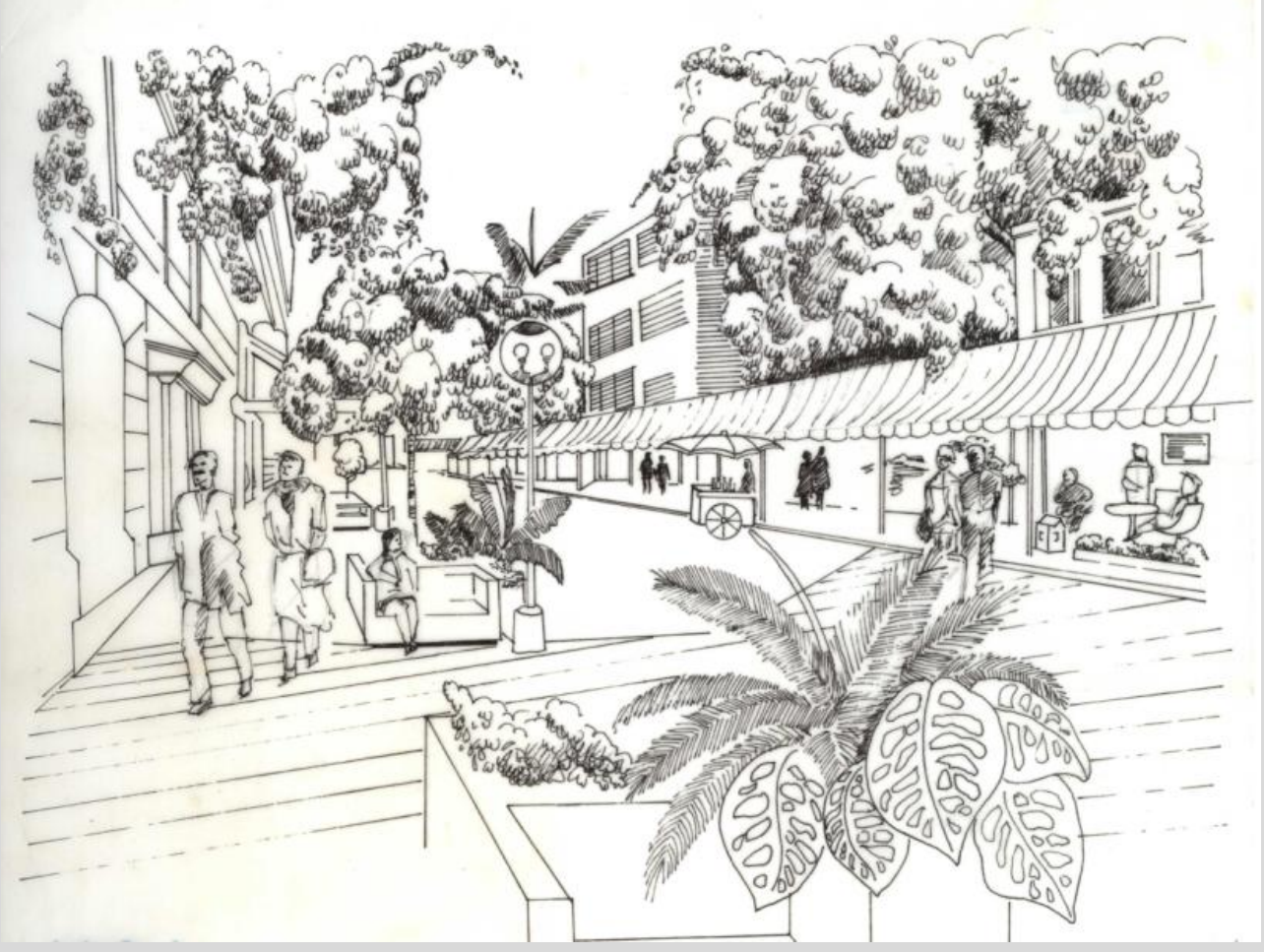

Figura $\mathbf{N}^{\circ}$ 14. Plano de las obras proyectadas en la plaza Santo Tomás. Imagen cortesía de Arq. Luis Fernando Aronne Castro.

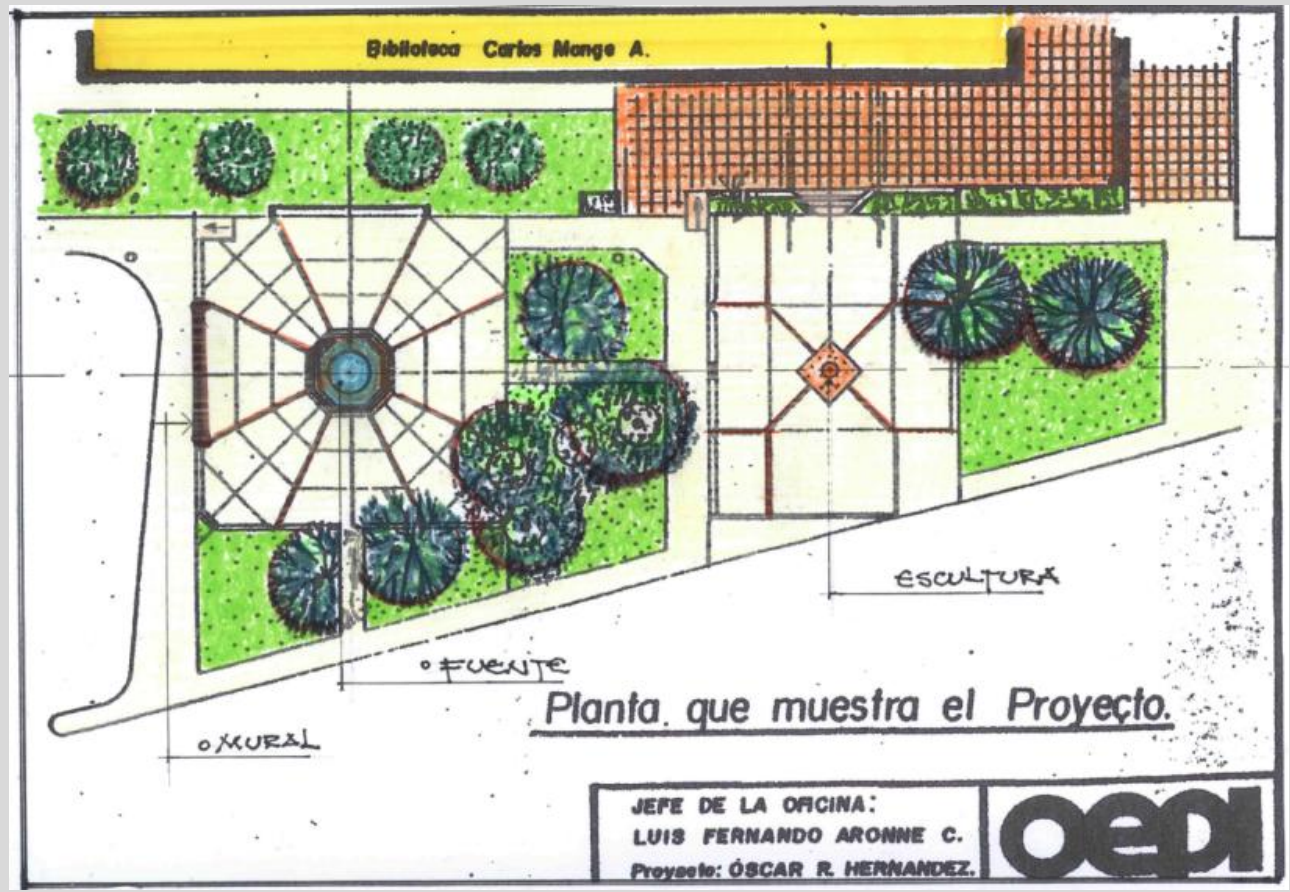


Revista Herencia, Vol. 31 (2), julio-diciembre, 2018.

Figura $\mathbf{N}^{\circ} 15$ a y b. Edificación construida para el mural que mostraría la historia de la fuente Cupido y el Cisne y la historia de la Universidad de Santo Tomás. Colección fotográfica Universidad de Costa Rica, AUROL.

a.

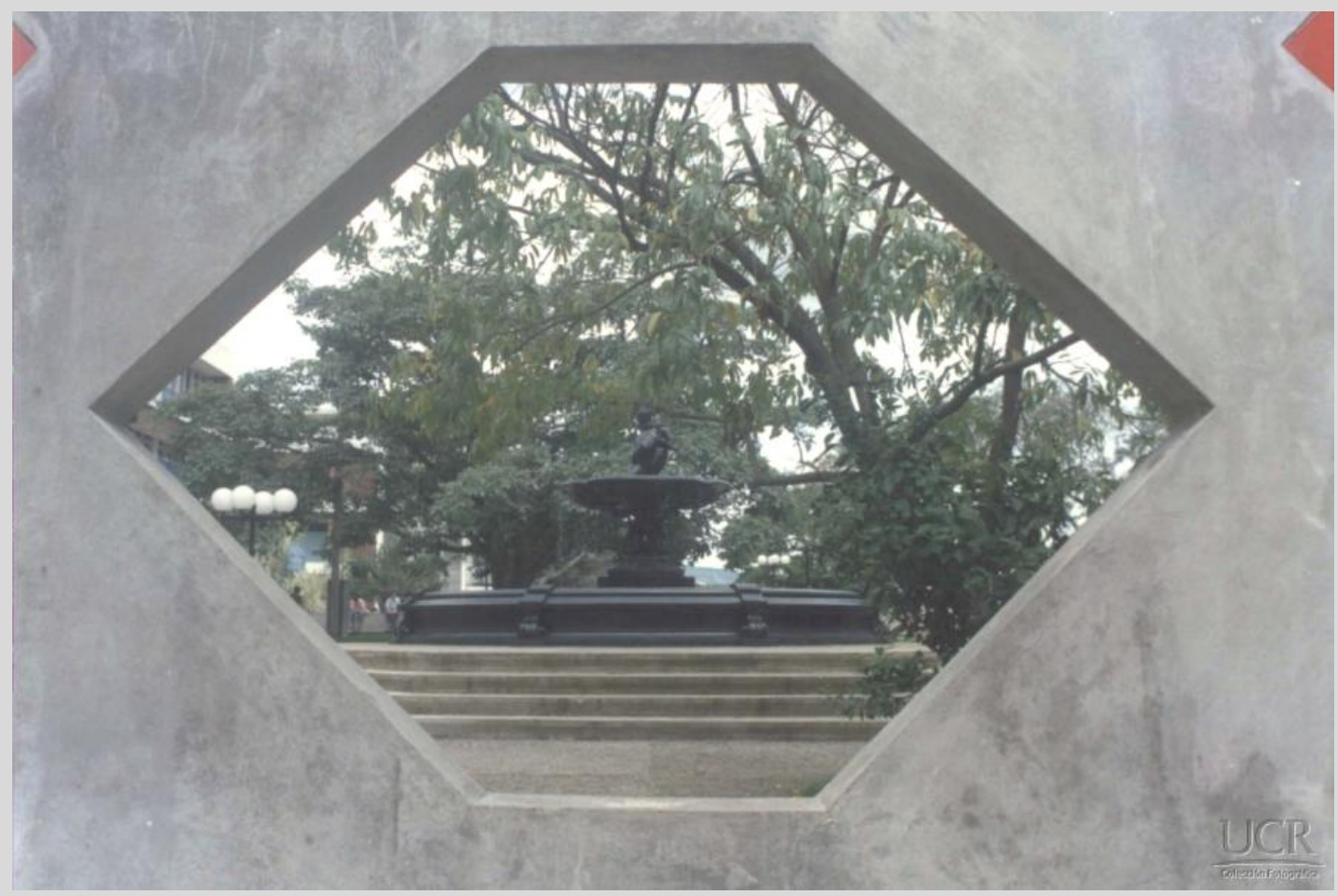

b.

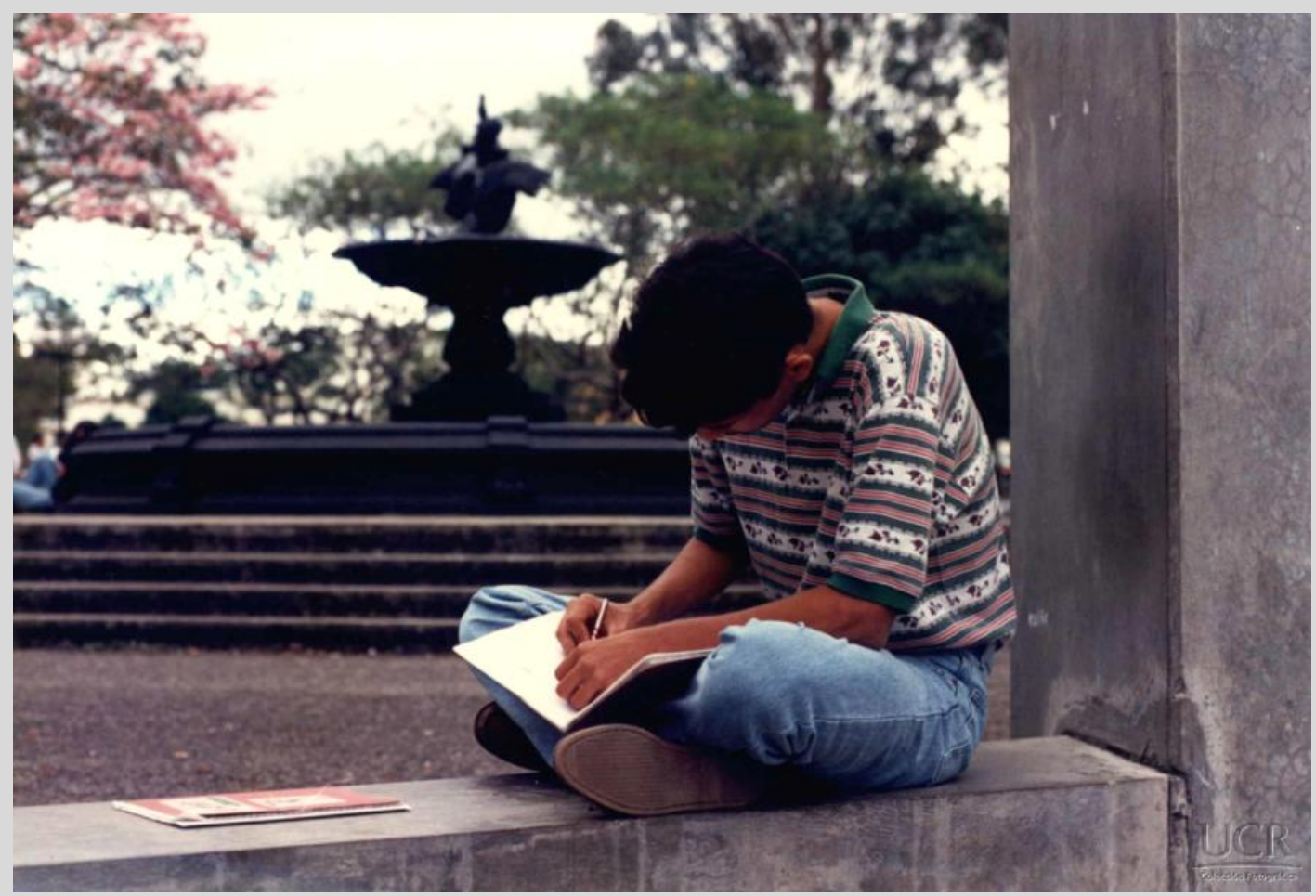


El proyecto Distrito Universitario no pudo realizarse tal como fue concebido, y la plaza, por razones presupuestarias, tuvo que ser limitada en espacio. Sin embargo, la decisión de colocar la fuente en ella, fue irreversible, y fue el propio rector, Fernando Durán Ayanegui quien intervino para lograr que la facultad de Agronomía cediera la fuente, para su nueva ubicación y propósito.

Para el año 1991, se concretó el proyecto de construir la plaza frente a la Biblioteca, cuyo nombre propuesto fue "plaza Santo Tomás", en recuerdo de la Universidad ancestro de la UCR (Actas del Consejo Universitario de la Universidad de Costa Rica. Sesión No.3816, ordinaria, 18 de febrero de 1992. Art 3, en Delgado s.f., p. 17).

La construcción de la plaza estuvo a cargo de la empresa "Constrial S.A". El contrato contemplaba la restauración y colocación de la fuente, además de una loza de cemento y escalinata de acceso. Para la restauración de la fuente, la empresa subcontrató al escultor Max Ulloa Royo, quien tuvo que reponer muchas piezas dañadas; el trabajo de arenado (limpieza abrasiva) de toda la escultura y la pila, se hizo en la empresa Westomatic, en Ochomogo, y el modelado y fundición de piezas, en el taller Industrial Villanea, en San Sebastián.

Figura No16. A la izquierda, con anteojos, el Ing. Lindbergh Blanco, gerente de la empresa constructora de la plaza; a la derecha, el escultor Max Ulloa, el restaurador de la fuente.

Colección fotográfica Universidad de Costa Rica, AUROL. 1991.

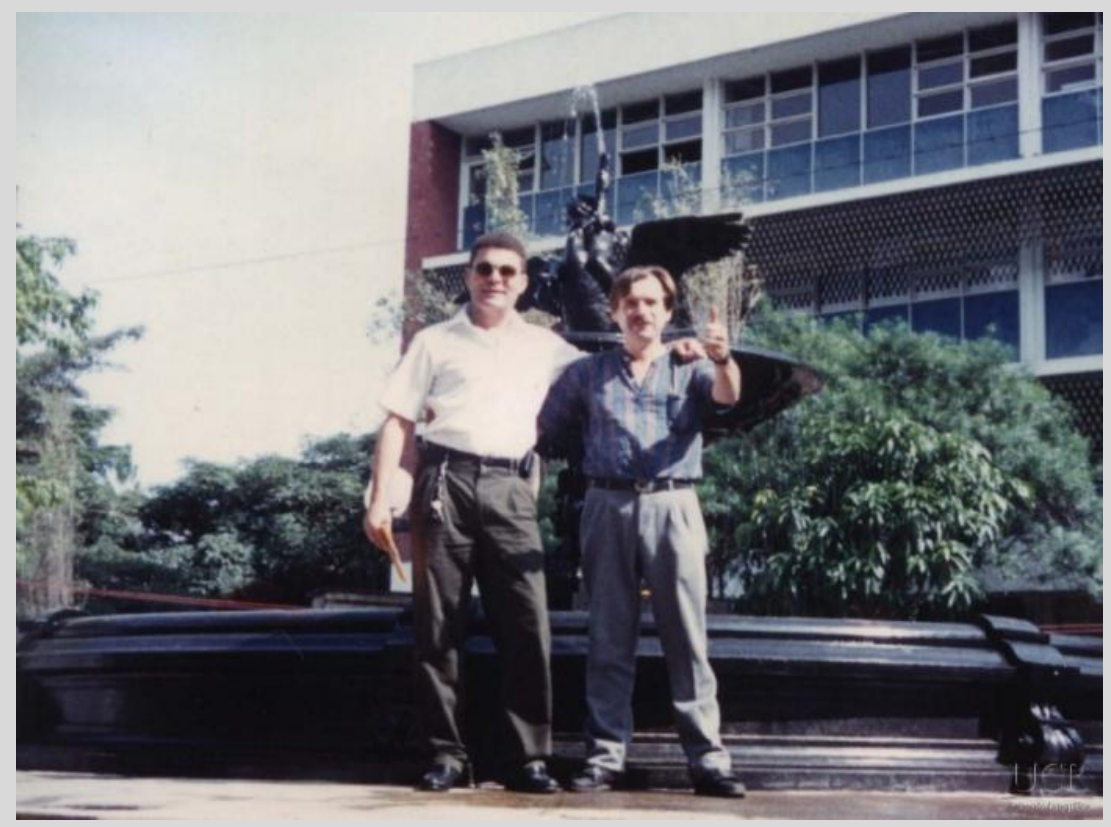


Con la fuente como motivo central, la plaza fue inaugurada el jueves 27 de febrero de 1992, por el rector Dr. Luis Garita junto con la exdiputada Rosemary Karpinsky.

Figura N¹7. Acto de inauguración de la plaza Santo Tomás, con la fuente Cupido y el Cisne, el día 27 de febrero de 1992. Al centro, la exlegisladora doña Rose Mary Karpinsky; a su izquierda, el rector don Luis Garita (qepd), y a su derecha, el periodista Manuel Emilio Morales. Foto de autor desconocido. Colección fotográfica Universidad de Costa Rica, AUROL. 1992.

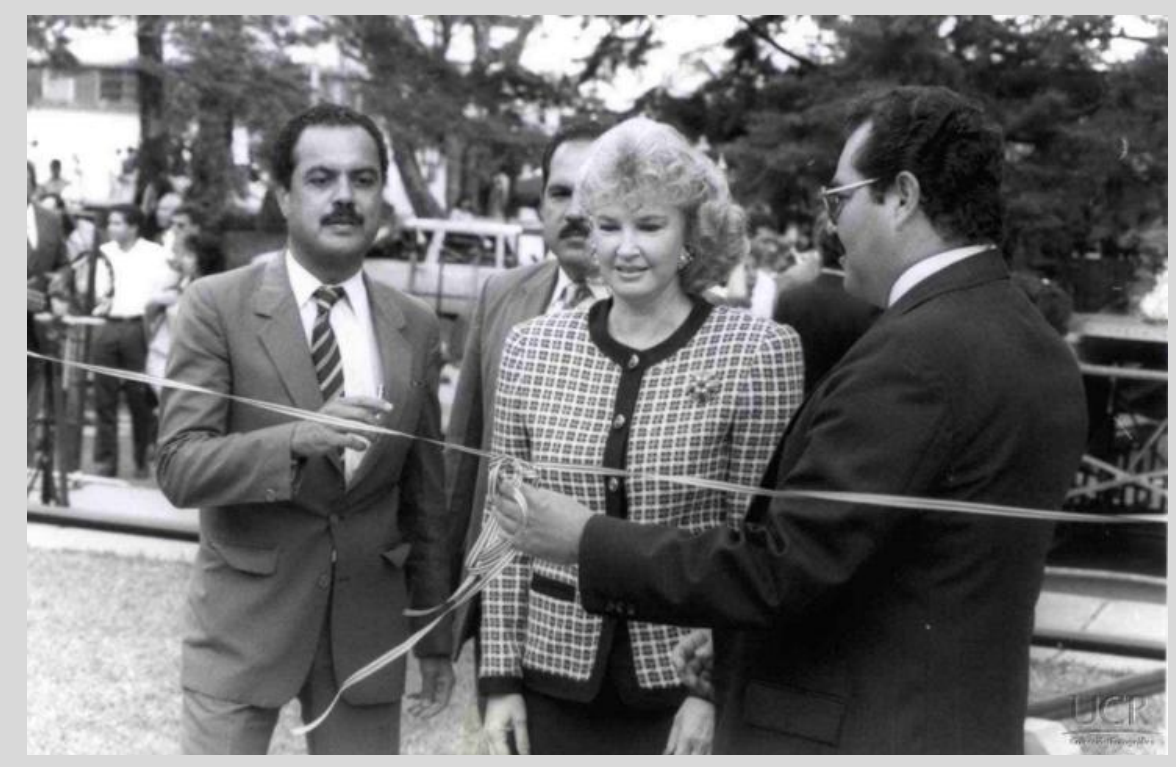

A finales del año 2013, gracias a la intervención de la Oficina de Servicios Generales, con el apoyo de la Vicerrectoría de Acción Social, se dispuso someter la fuente a una nueva restauración. El proyecto fue coordinado por el arquitecto Javier Campos y ejecutado por la restauradora profesional Ana María Moraleda, recomendada por el Ministerio de Cultura y Juventud. Ella (junto con sus ayudantes) ejecutó la restauración, basada en los principios internacionales sobre conservación y rehabilitación de bienes culturales. La obra se finalizó en abril de 2014.

Al alcanzar los 150 años en este año 2018, la fuente ha permanecido la mitad de su vida al abrigo y calor de la Universidad, que desde el principio la acogió con entusiasmo, y vino a ser punto de solaz y reflexión para alumnos, profesores y visitantes. Discretamente, diría que con un perfil bajo, esta fuente ha sido testigo de casi toda la historia universitaria. Ha visto el florecimiento y consolidación de la ciudad universitaria, sus escuelas, facultades y satélites; también ha visto a todos los rectores, todos los congresos universitarios, las federaciones 
estudiantiles, las semanas universitarias, y también las luchas internas y las luchas sociales externas.

Ha sido un fanal, cuya luz nos alumbraba desde siempre, pero al que no prestábamos suficiente atención. Sin embargo, con el paso de los años, de manera espontánea, su figura empezó a volar, al extremo que ya la vemos invariablemente en el paisaje universitario, casi tanto como el escudo. Su imagen aparece hoy asociada a simposios, foros institucionales, actividades oficiales, material postal, publicidad, en la medalla conmemorativa del 75 aniversario, etc. En fin, es un símbolo ya muy arraigado en el imaginario de la comunidad universitaria.

Son muchas las personas y entidades que han hecho posible la existencia y permanencia de esta valiosa obra. Desde los mineros que extrajeron el hierro, el escultor y los fundidores; las autoridades visionarias que la compraron en Inglaterra; los boyeros que la trajeron hasta San José, por caminos imposibles; los restauradores, obreros y artesanos; los soñadores que la velaron para que no se perdiera, fotógrafos y escritores; también los miembros de la comisión del sesquicentenario de la fuente, y en especial a las autoridades universitarias que entendieron a don Rodrigo Facio Brenes, cuando en mayo de 1960, al inaugurar el edificio de la Facultad de Ciencias Económicas, dijo estas inolvidables palabras:

"La clave de la vitalidad y el éxito de nuestro campus es que lo material responde a las necesidades; tiene el tamaño y se ajusta a los requerimientos del mundo espiritual y de la cultura. Y todo: muros y planes de estudio, piedras y métodos de investigación, estén inspirados por las urgencias del espíritu y puestos al servicio de la juventud costarricense".

Esta fuente, parte esencial del paisaje universitario y que lo ha sido también de Costa Rica por un siglo y medio, también responde a esta visión y responsabilidad que nos legó don Rodrigo. 


\section{BIBLIOGRAFÍA}

Anónimo (1928). Cuando fui con mi padre a Puntarenas por la fuente de la plaza Principal. La Nueva Prensa, diario de la tarde, 30 de agosto, p. 9.

Delgado, J. M. (s. f.) La fuente peregrina. Documento inédito.

Powell, J. (2013). The Boy and Swan Notes. Documento inédito.

Núñez, F. (1944). Con fondos del ministro Francisco María Iglesias se construyó el parque Central de San José. Diario de Costa Rica, 9 de enero, p. 1.

Núñez, F. (1966). La fuente del parque Central. La Prensa Libre, 29 de noviembre, p. 2-A.

Orozco, S. (2016). Delfines, leones y tritones. Fuentes victorianas de hierro en las plazas y parques de Costa Rica (1868-1880). Revista Herencia 29(1), 95 - 140.

\section{FUENTES PRIMARIAS}

Actas del Consejo Universitario de la Universidad de Costa Rica (1989). Sesión No.3544, ordinaria, 28 de febrero de 1989.

Oficio de Rectoría (No. R-364-58). 14 de mayo de 1958. AUROL. 